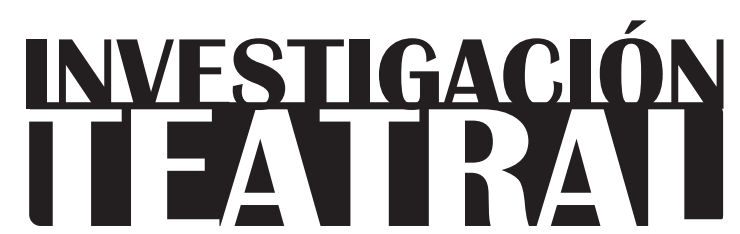

Revista de artes escénicas y performatividad

Vol. 9, Núm. 13

abril-septiembre 2018

Segunda época

ISSN impreso: 1665-8728

ISSN electrónico: 2594-0953

Universidad Veracruzana

Reseña de la

puesta en escena:

\title{
La extinta variedad del mundo de Alberto Villarreal
}

Saúl Rivas Meléndez*

\footnotetext{
* Maestría en Artes Escénicas, Universidad Veracruzana, México.

e-mail:dimo14@hotmail.com
} 


\section{La extinta variedad del mundo de Alberto Villarreal} a extinta variedad del mundo, obra que Alberto Villarreal escribió y dirigió para la Compañía Titular de Teatro de la Universidad Veracruzana, fue uno de los espectáculos más notables estrenados durante 2017 en la ciudad de Xalapa, Veracruz. Se trató de un montaje situado en las fronteras del teatro convencional, por su trabajo con una estética performativa que se vale de acciones físicas, objetos, música en vivo, máscaras y disfraces grotescos para generar un universo simbólico de lectura amplia para el espectador. El cuerpo del los actores se llevó al límite de la expresividad gestual y coreográfica sin recurrir al uso de la palabra hablada.

La extinta variedad del mundo realizó una aguda parodia a las figuras de autoridad, escenificando a 'gobernantes' que ya ni caminar quieren, pero ejercen violencia sobre los ciudadanos. Se realizaba así mismo una crítica a la manera en que las multitudes siguen ciegamente a los líderes o políticos. La puesta en escena planteó preguntas como: ¿qué se gana y que se pierde cuando homogenizamos el mundo?, ¿puede más el temor a lo diferente que la curiosidad por conocer lo desconocido?, o ¿hasta qué punto somos cómplices del fascismo o partícipes de la violencia de Estado? La obra se presentó del 10 al 24 de noviembre de 2017 en la sala Dagoberto Guillaumin del Teatro del Estado Gral. Ignacio de la Llave, con capacidad para 260 personas, sobre un escenario 'a la italiana'. A la función que aquí se reseña, la del día 11 de noviembre, acudimos entre 100 y 120 personas, en su mayoría jóvenes estudiantes de la Universidad Veracruzana; aunque también había espectadores de mayor edad, de entre 45 y 70 años, incluyendo algunos académicos de la misma institución.

Desde que entraba a la sala, el espectador podía ver, en lugar del telón, una malla negra, traslúcida, que cubría todo el rectángulo que conforma el frente del escenario. Detrás de 
INVESTIGACIÓNTEATRAL

Revista de artes escénicas y performatividad

Vol. 9, Núm. 13

abril-septiembre 2018
La extinta variedad del mundo

de Alberto Villarreal

Saúl Rivas Meléndez

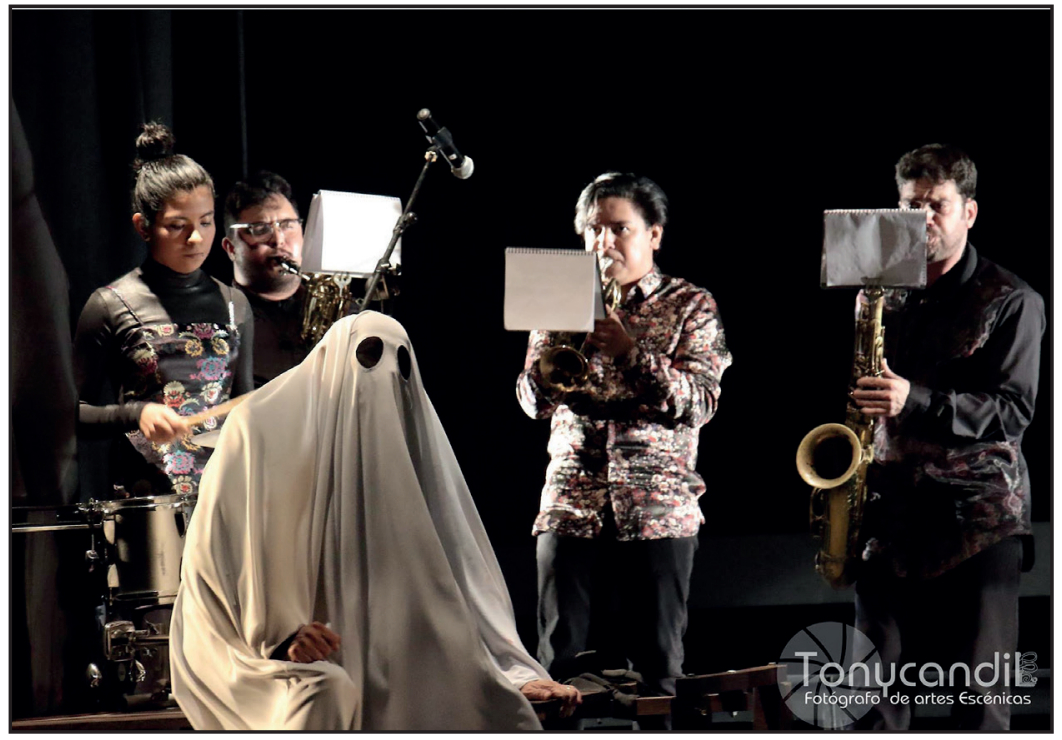

La extinta variedad del mundo, de Alberto Villarreal. Escena con el actor Jorge Castillo y los músicos: Ricardo Uresti (trompeta), Adal Pérez (saxofón barítono), Leandro Luis Rey (saxofón) y Kristina Sánchez (percusiones) Fotografía de Luis Antonio Marín, archivo Candileja, 2017.

ésta se observaba una fila de bancas de color negro, colocadas de frente al público, y dos enormes ventiladores que funcionaban y movían con el aire la quietud de los objetos.

El público poco a poco ocupó sus lugares. No hubo anuncio de primera, ni de segunda, ni de tercera llamada. Fuimos sorprendidos por la aparición de dos actores, Rosalinda Ulloa y Félix Lozano. Sus voces y una campana evocaban la presencia de una vaca, en un ambiente rural. Enseguida, emergieron del fondo a la izquierda, en solemne y cadenciosa procesión, el resto de los actores del elenco: Jorge Castillo, Miriam Cházaro, Juana María Garza, Luisa Garza, Gema Muñoz, Luz María Ordiales y José Palacios, todos vestidos de negro, con la particularidad de que Cházaro y Palacios llevaban máscaras de perros, creando una sensación de extrañeza ante lo diferente. Todos ellos tiraban de un trineo de madera donde viajaba la banda musical, compuesta por cuatro integrantes: Ricardo Uresti (trompeta), Adal Pérez (saxofón barítono), Leandro Luis Rey (saxofón) y Kristina Sánchez (percusiones).

\section{La unificación gestual}

La obra se tejió por medio de símbolos visuales, como trajes masculinos de saco y corbata, o máscaras de perros que portaban algunos actores y que reforzaban la animalidad con la gestualidad corporal; y símbolos auditivos, como los golpes metálicos que acompañaban la acción de disparar una escopeta, o la música que acompañó en todo momento y, que cambiaba, según la escena. Podría decirse que el montaje superó el textocentrismo que critica Hans 
Thies-Lehmann, desechando el montaje convencional de un texto dramático. No obstante, se usaron textos, como uno aparentemente apócrifo que se proyectó sobre el escenario entre una escena y otra, y que describía oscuras formas de venganza con un lenguaje evocador de libros de texto antiguos, lo cual producía un distanciamiento irónico.

La banda de música se quedó en un lugar visible del escenario, era parte palpable del conjunto de elementos que crearon el universo de la obra. Con las notas de sus instrumentos marcaron el tono, a veces fúnebre, a veces festivo, otras veces inquietante o enigmático, de cada escena. Dos parejas se pusieron a bailar, y llamaba la atención que un integrante de cada pareja llevaba puesta una máscara de perro. Mientras bailaban, marcaban el ritmo con un zapateado veracruzano, que auditivamente generó otro código simbólico que contextualizó el montaje en las proximidades culturales de Xalapa.

En una escena siguiente, entró el actor Jorge Castillo quien fue remolcado sobre un diablito. Por su vestimenta, compuesta por un traje sastre de color negro, y por la forma en que éste se relacionaba con los demás personajes de la puesta en escena, el espectador entendió que él era un líder político que se encontraba cerca de la extinción de su vida. El hecho de que él no pudiera valerse por sí mismo remitía a esta interpretación. Efectivamente, unos instantes después de su aparición en escena, este personaje murió.

En la parodia de un ritual funerario fue investido de fantasma. Le colocaron una manta blanca con agujeros en los ojos, el cliché primero fue un símbolo que de tan gastado, repetido y conocido se volvió un lugar común, que como espectadores decodificamos sin esfuerzo y con gracia. Después fue su viuda (la octagenaria y estupenda actriz Luz María Ordiales) quien dictó las normas que ese grupo de personas debían repetir.

Ella se colocó de pie en el centro de la escena, se puso un vaso en la cabeza y se quedó inmóvil durante algunos minutos. Durante este tiempo los demás actores imitaron el gesto de la mujer. Crearon una cadena de movimientos: uno de ellos, José Palacios, se colocó una veladora de vaso de vidrio sobre la cabeza; se hincó ante otra actriz, Juana María Garza, quien la encendió sin tomarla con las manos; él se puso de pie; caminó hacia atrás del escenario; dejó caer la veladora en sus manos y volvió a iniciar la secuencia. Lo mismo realizaron todos y cada uno de los demás actores. La variedad de los seres que habitaban ese universo ficticio había sido aniquilada.

En la escena siguiente, la viuda no se había movido aun del lugar donde se posó. Los demás actores se detuvieron y miraron hacia atrás del escenario. En ese momento, entró lentamente un hombre empujando su carrito de camotes, como si hubiese entrado de la calle. El vendedor de camotes no parecía estar actuando, empujaba su carrito de forma natural, lo que contrastaba con la gestualidad mecánica y repetitiva de los demás intérpretes. Se detuvo en el centro de la escena y accionó el pitido del carrito, que en el contexto mexicano todos asociamos con su oficio. Fue un silbido estruendoso que inundó todo el foro. 
Estábamos frente a una imagen aparentemente inmóvil, pero cinética gracias al viento que acariciaba las telas, el movimiento del humo, y las lenguas de fuego sobre las brasas de carbón del carrito de camotes. El momento duró casi veinte segundos, los cuales en el tiempo de la escena parecieron una eternidad, y me hizo pensar en los paisajes escénicos de Robert Wilson (Lehmann 142). Aquí finalizó el primer acto.

El segundo acto inició con la escena de los partos. Estaban un hombre y otra mujer con máscaras de perro. También estaban varias mujeres vestidas con batas blancas con vientres prominentes. Estos dos elementos sugirieron una situación: el embarazo. Un lugar: un sanatorio. Actuaron de manera simbólica. El cerebro del espectador completaba o construía todo lo demás. Yo, por ejemplo, pensé que el líder político que murió en el acto anterior era un 'cabrón' que le 'tiraba' a lo que se movía.

Enseguida, todas las mujeres dieron a luz, se sacaron de debajo de la bata muñecos, sin la intención de aparentar más de lo que estos objetos eran. Incluso la mujer-perro del acto anterior parió a varios perritos de peluche. Hubo risas por todo el teatro. Entró otra mujer con escopeta en mano y disparó a los recién nacidos; cargó su escopeta vacía y disparó de nuevo. El sonido de la detonación fue simulado golpeando un tambo de metal, sincronizado con la caída al piso de los muñecos. Hasta los perritos de peluche fueron asesinados.

Por si a alguien no le había quedado clara la muerte de los infantes, la escena concluyó con la colocación de cal sobre los muñecos. En este respiro pensé en dos textos: uno el Ubu Rey, de Alfred Jarry. El otro que me llegó a la mente fue El rey se muere, de Ionesco. Ambos tienen por personaje principal al hombre común y ordinario que se vuelve rey idiota y que no es capaz de dirigir con eficacia su pequeño reino. En la obra que estaba viendo el líder muerto era un Ubu o un rey a lo Ionesco.

En la siguiente escena todos los actores que participaban se relacionaban entre sí a partir del uso extraordinario y uniforme de un vaso de vidrio. La realización se basó en un alarde colectivo de equilibrio, de conciencia corporal y conciencia de la relación del actor con el objeto. Las escenas se tejieron a manera de coro. Afirma Sarrazac que en el teatro contemporáneo "el recurso al coro, es a menudo, en una época de desencanto del mundo, la ocasión de una queja fundamental que recuerda la maldición de la desunión, la insalvable separación de los seres." (66) Las actrices ataviadas con vestidos de noche, se sentaron en las bancas una junto a otra. Hombro con hombro, colocaron los vasos de vidrio sobre la cabeza de quien se encontraba a su izquierda; con una ligera inclinación de cabeza dejaron caer el vaso en sus propias manos y volvieron a efectuar la misma cadena de movimientos en un bucle que pareció eterno.

A partir de esta circulación corporal, en apariencia simple, con base en la repetición y en la acción coral, se crearon grandes estructuras visuales, concatenadas por el virtuosismo 
INVESTIGACIÓNTEATRAL

Revista de artes escénicas y performatividad

Vol. 9, Núm. 13

abril-septiembre 2018
La extinta variedad del mundo

de Alberto Villarreal

Saúl Rivas Meléndez

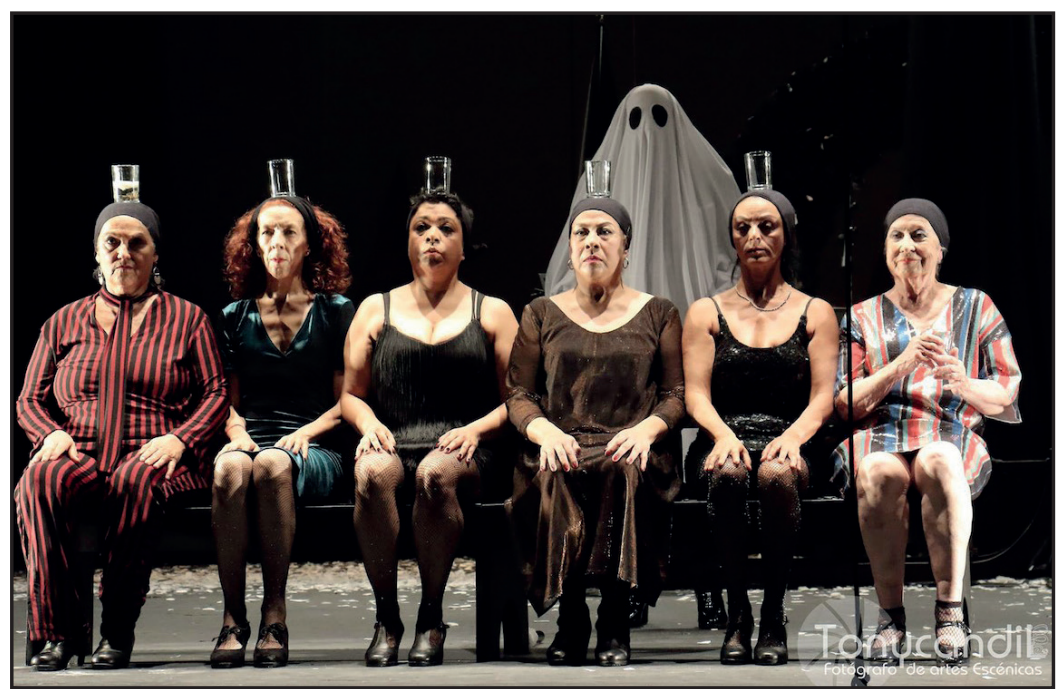

Escena de la obra La extinta variedad del mundo, de Alberto Villarreal. Esena con las actrices Miriam Cházaro, Juana María Garza, Luisa Garza, Gema Muñoz, Luz María Ordiales, y Rosalinda Ulloa, y el actor Jorge Castillo (detrás de ellas). Fotografía de Luis Antonio Marín, archivo Candileja, 2017.

de la precisión que cada uno de los actores adquirió en el trabajo durante los ensayos. Una y otra vez realizaron la secuencia sin equivocaciones. Los actores se encontraban al servicio de un objetivo mayor que los despojó de su individualidad y los homologó en pro de un engranaje perfecto. Si hubiéramos visto a uno solo de ellos ponerse el vaso sobre la cabeza y moverse, el recurso se hubiera agotado pronto, pero el conjunto les dotó de otra fuerza que mientras más se repitió, más impactante y extraordinario se volvió.

A lo largo de los sesenta minutos que duró la obra, los actores se mantuvieron completamente mudos. No es casual que en este montaje se decidió prescindir enteramente de la voz del actor. La voz es una de las características que dotan al ser humano de individualidad. Por lo tanto, su presencia en el mundo enriquece la variedad del mundo. Irónicamente, el director decidió dejarla fuera de esta puesta en escena. En cambio, Alberto Villarreal sacó el mayor provecho de las capacidades corporales de los veteranos actores de la Compañía Teatral de la UV, así como de los recursos técnicos a nivel iluminación, audio y tramoya, sin renunciar a la particular poética escénica que lo caracterizan como director.

\section{Bibliografía}

Alvarado, Ana. Teatro de objetos. Manual dramatúrgico. Buenos Aires: Inteatro, 2015.

Innes, Christopher. El teatro sagrado. El ritual y la vanguardia. México: Fondo de Cultura Económica, 1992.

Lehmann, Hans-Thies. Teatro posdramático. México: Paso de Gato, 2013. 


\section{Ficha técnica de La extinta variedad del mundo}

ORTEUV

Dramaturgia, dirección, iluminación y diseño de espacio: Alberto Villarreal

Asistente de dirección: Yair Gamboa.

Diseño de arte, coreografía y vestuario: Esmirna Barrios.

Escenografía: Iván Cervantes.

Elenco: Jorge Castillo, Miriam Cházaro, Juana María Garza, Luisa Garza, Félix Lozano, Gema Muñoz, Luz María Ordiales, José Palacios y Rosalinda Ulloa.

Diseño sonoro y arreglos musicales: Joaquín López Chas.

Música de: Henry Purcell, Dimitri Shostakovic, Gigi D’Lesio, Beirut, Demian Cerimovic, Leandro Luis Rey, Ricardo Uresti y Joaquín López Chas.

Interpretación e improvisación musical: Ricardo Uresti (trompeta), Adal Pérez (saxofón barítono), Leandro Luis Rey (saxofón), Kristina Sánchez (percusiones) y Yair Gamboa (piano)

Director artístico de la Compañía Titular de Teatro de la Universidad Veracruzana: Luis Mario Moncada. 